\title{
ANALISIS TEKSTUAL KOYUNBABA KARYA CARLO DOMENICONI: BENTUK DAN STRUKTUR BAGIAN I MODERATO
}

\author{
Birul Walidaini $^{1}$ \\ ${ }^{1}$ Prodi Pendidikan Seni Musik, Universitas Negeri Yogyakarta, Jl. Colombo Yogyakarta No.1, Kec. Depok, \\ Kabupaten Sleman, Daerah Istimewa Yogyakarta, Indonesia \\ ${ }^{(*)} \bowtie$ (e-mail) birul@uny.ac.id ${ }^{1}$
}

\begin{abstract}
Abstrak
Penelitian ini bertujuan untuk menganalisis bentuk dan struktur musik bagian pertama "I MODERATO" dari Koyunbaba karya Carlo Domeniconi. Penelitian ini merupakan penelitian deskriptif kualitatif. Subjek penelitian ini yaitu teks atau partitur lagu Koyunbaba (Suite Für Gitarre Op.19) karya Carlo Domeniconi. Penelitian difokuskan pada bentuk dan struktur musik dari koyunbaba bagian pertama yaitu I Moderato. Data utama dalam penelitian ini adalah teks atau partitur dari koyunbaba. Hasil penelitian menunjukkan bahwa jumlah birama dalam bagian pertama I Moderato ini adalah empat puluh dua birama. Setelah dianalisis strukturnya berdasarkan ilmu bentuk dan analisis musik, maka terdapat delapan periode atau kalimat yang didalam setiap periode berisikan anak kalimat dan motif. Pada bagian pertama I Moderato, motif- motif yang di tuliskan merupakan motif yang berpotensi diulang pada bagian- bagian selanjutnya. Bagian pertama ini juga berfungsi sebagai introduction atau pengenalan terhadap karya koyunbaba ini. Dalam bagian pertama ini ditemukan motif- motif yang cukup beragam karena dalam sejarahnya karya ini merupakan hasil improvisasi yang dituliskan ke dalam partitur.
\end{abstract}

Kata kunci: gitar klasik, bentuk musik, koyunbaba, carlo domeniconi, analisis tekstual

\begin{abstract}
This study aims to analyze the form and structure of the music in the first part of "I MODERATO" by Carlo Domeniconi's Koyunbaba. This research is a qualitative descriptive study. The subject of this research is the text or score of the song Koyunbaba (Suite Für Gitarre Op.19) by Carlo Domeniconi. The research focused on the form and structure of the music of the first part of the koyunbaba, namely I Moderato. The main data in this study are text or scores from koyunbaba. The results showed that the number of bars in the first part of I Moderato was forty-two bars. After analyzing the structure based on form science and music analysis, there are eight periods or sentences in which each period contains clauses and motives. In the first part of I Moderato, the motifs that are written are those that have the potential to be repeated in the following sections. This first part also serves as an introduction or introduction to this work of Koyunbaba. In this first part, a variety of motifs are found because in its history this work was the result of an improvisation written into sheet music.
\end{abstract}

Keywords: classical guitar, musical form, koyunbaba, carlo domeniconi, textual analysis.

This work is licensed under a Creative Commons Attribution-ShareAlike 4.0 International License. Copyright @ 2020 Birul Walidaini

Proses Artikel

Diterima 19-11-2020; Revisi 04-12-2020; Terbit Online 08-12-2020 


\section{Pendahuluan}

Manifestasi musik dapat dijadikan sebagai salah satu medium dalam pengungkapan ekspresi dan kreasi manusia (Hidayatullah, 2020; Parmadie, 2016). Merujuk pada perihal musik sebagai medium, sesuai dengan pernyataan (Yensharti, 2019) yang mengatakan bahwa musik dapat juga dijadikan sebagai media ungkap pikiran atau perasaan manusia melalui bunyi yang diformulasikan ritme dan nada sebagai unsur dasarnya. Dalam kemasan penyajiannya musik dibedakan menjadi beberapa jenis yaitu musik yang memakain unsur vocal dan bahasa, namun ada pula musik yang tidak memerlukan unsur bahasa atau yang lebih dikenal dengan musik instrumental (Sinaga et al., 2019; Winangsit \& Sinaga, 2020). Musik Instrumental adalah jenis musik yang tidak ada vokal atau lirik, vocal utama digantikan dengan suara instrument musik. Apapun jenis dan fungsinya, karya musik diantaranya mengangkat tentang pengalaman, kehidupan sehari-hari serta kondisi sosial dimana musik itu dibuat (Niswati Khoiriyah, 2017)

Perkembangan teknologi dan budaya masyarakat dapat memberikan pengaruh pada sebuah karya musik (Widyanta, 2019). Hal ini dapat dilihat dari latar belakang tempat dimana sebuah musik itu dibuat atau dimainkan, alat musik apa yang dilibatkan, dan jenis musik bagaimana yang di angkat. Faktor diatas memberikan pengaruh dalam mengapresiasi sebuah karya musik, sehingga untuk mencapai pemahaman sebuah karya musik diperlukan pengetahuan yang mendalam tentang bagaimana kondisi masyarakat pada saat sebuah karya musik itu dibuat. Pada tingkat pemahaman ini peminat musik perlu untuk mempelajari aspekaspek yang menunjang dalam proses memahami sebuah karya musik dengan menambah pengetahuan dari berbagai sumber, terlebih untuk karya musik instrumental karena musik instrumental tidak melibatkan unsur bahasa secara verbal didalamnya melainkan hanya rangkaian nada dan harmoni yang dikemas untuk alat musik, salah satunya adalah gitar klasik.

Gitar klasik tergabung dalam tiga bagian utama yaitu kepala, leher, dan badan. Gitar klasik di kalangan masyarakat Indonesia memang tidak begitu popular jika dibandingkan dengan string acoustic guitar maupun electric guitar (Yuniarko, 2020). Teks atau partitur merupakan unsur terpenting dalam proses komunikasi yang didalamnya melibatkan komponis dan pemain gitar. Pemain gitar menginterpretasikan maksud dari komponis yang dituliskan pada partitur. Partitur merupakan media yang didalamnya berisi tanda-tanda (musik) yang dimaksudkan untuk mengungkapkan pesan dari komponis yang ingin disampaikan kepada pemain gitar dan kemudian disajikan kepada audience. Komponis tidak begitu saja membuat sebuah karya musik, karena komponis pasti mempunyai beberapa alasan, antara lain: proses dan hasil interaksinya dengan alam dan lingkungan sekitar, kejadian-kejadian yang pernah dilalui, dan alasan yang lainnya (Andaryani, 2019).

Proses interpretasi sebuah teks, bisa menciptakan beragam makna dan pengungkapan dari masing-masing pemain gitar klasik. Perihal tersebut sangat dipengaruhi oleh karakter dan wawasan dalam permainan gitar klasik. Dalam hal ini, peranan teks atau partitur kembali menjadi rujukan karena di dalamnya terdapat unsur-unsur musik seperti perubahan tempo dan dinamika yang bisa menjadi acuan bagi para pembaca teks atau pemain musik. Penginterpretasian teks atau partitur sebuah karya musik dengan mengikuti tanda-tanda didalamnya akan lebih memungkinkan tersampaikannya pesan yang tertuang dalam teks atau 
partitur secara maksimal, aspek lain yang menjadi bagian penting dalam penginterpretasian sebuah teks musik adalah latar belakang sejarah dalam sebuah karya musik dimana faktor ini dapat membuat pemain bisa lebih menjiwai dan dapat menyampaikan pesan yang terkandung dalam karya kepada audience.

Beberapa pembagian zaman dalam sejarah musik terdiri atas renaisance, baroque, classic, romantic, dan modern. Masing-masing periodik tersebut mempunyai komponis serta gaya musik yang berbeda. Salah satu komponois pada zaman tersebut adalah Carlo Domeniconi. Carlo Domeniconi adalah seorang komposer sekaligus pengajar musik. Pengalamannya sebagai pengajar membuat ia berpindah dari satu negara ke Negara lain. Salah satu negara yang pernah menjadi tempat tinggalnya adalah Turki dimana dia menjadi pengajar di Conservatory of Istanbul. Musik tradisional Turki banyak memberikan pengaruh pada hasil karya yang diciptakan Carlo Domeniconi (Harries, 2014).

Salah satu karya Carlo Domeniconi yang terkenal yaitu Koyunbaba (Suite Für Gitarre Op.19). Koyunbaba merupakan karya musik yang diciptakan untuk solo gitar yang mengambil judul dari salah satu tempat di negara Turki. Koyunbaba mempunyai keunikan tersendiri dibanding karya musik yang lain. Hal tersebut dikarenakan, Domeniconi tidak memberikan sukat atau tanda birama, dimana seharusnya tanda birama merupakan poin penting dalam penulisan karya musik karena tanda birama menentukan ketukan, aksen, dan penilaian pada setiap not yang akan dimainkan. Selain itu, dalam komposisi Koyunbaba ini juga menggunakan tuning dawai gitar yang tidak berbeda dengan tunning gitar pada umumnya.

Penjabaran tentang bentuk dan struktur sebuah karya bertujuan agar pemain gitar lebih memahami sebuah karya secara lebih rinci. Upaya ini memerlukan proses analisis bentuk dan struktur secara musikal dimana sebuah karya akan diurai berdasarkan satuan- satuannya. Leon Stein (1962) dalam bukunya yang berjudul Structure \& Style The Study and Analysis od Musical Form mendeskripsikan aspek dalam teks musik mulai dari satu kalimat utuh atau periode sampai pada bagian terkecil yaitu motif (Stein, 1962).

Struktur merupakan suatu sistem yang memperlihatkan adanya keteraturan dalam menyusun segenap unsur-unsurnya (Paulus et al., 2010). Motif merupakan bagian terkecil dalam musik dan mengandung unsur musikal (Firmansyah, 2015; Prier \& Widyawan, 2011; Wardani, 2020). Tema adalah ide pokok yang didalamnya terdapat unsur-unsur musikal utama pada sebuah komposisi, tema masih harus dikembangkan lagi hingga membentuk sebuah karya musik secara utuh (Muhammad, 2003). Frase sebagai satu kesatuan (unit) yang secara konvensional terdiri atas 4 birama panjangnya dan ditandai dengan sebuah kadens. Frase dibagi menjadi dua yaitu frase antesenden dan frase konsekuen. Berikut dijelaskan pengertian frase antesenden dan konsekuen (Putra, 2019). Figure, adalah unit konstruksi terkecil dalam musik. Terdiri dari setidaknya satu ritme karakteristik dan satu interval karakteristik, terdiri dari sedikitnya dua nada sampai sebanyak dua belas nada. motif kadangkadang digunakan sebagai sinonim dengan figur (Stein, 1962). Kadens adalah istilah musik yang menunjukan akhir dari suatu bagian musik. Sedangkan periode adalah gabungan dua frase atau lebih dalam sebuah wujud yang bersambung sehingga membentuk sebuah unit seksional.

Berdasarkan deskripsi latar belakang di atas, penelitian ini akan mengkaji tentang bagaimana analisis tekstual (bentuk dan struktur) pada lagu berjudul Koyunbaba pada bagian pertama yaitu I Moderato. Penelitian ini bertujuan untuk menganalisis dan mendeskripsikan 
bentuk dan struktur karya musik berjudul Koyunbawa pada bagian I Moderato. Manfaat penelitian ini diharapkan dapat memberikan gambaran dan pemahaman secara lebih teliti untuk pemain gitar maupun pihak- pihak lain yang sedang melakukan pendalaman tentang karya ini.

\section{Metode}

Penelitian ini merupakan jenis penelitian kualitatif, yaitu penelitian yang memberikan gambaran mengenai keadaan atau gejala yang terjadi tanpa melepaskan objek yang diteliti. Hal tersebut dikarenakan data yang terkumpul berbentuk kata-kata atau gambar yang bersifat deskriptif (Sugiyono, 2011). Dalam penelitian kualitatif data berasal dari dokumentasi penelitian, pengawasan, evaluasi, pengamatan pendahuluan dan pernyataan dari narasumber yang dipercaya. Hipotesis dalam penelitan kualitatif bersifat menemukan teori bukan merumuskan atau merinci hipotesis secara jelas sebelum terjun ke lapangan. Dengan demikian, penelitian ini merupakan penelitian yang dilakukan dengan menggunakan metode kualitatif dengan menggunakan beberapa kajian musikologi yang bersifat deskriptif dengan tujuan mencari penjelasan rinci tentang fenomena sistem tanda yang ada pada teks Koyunbaba.

Penelitian ini menggunakan beberapa langkah kerja, yaitu membaca (memainkan) teks, menyimak, mengamati, dan menganalisis teks music (partitur) Koyunbaba. Data utama dalam penelitian ini yaitu teks partitur dari lagu Koyunbaba (Suite Für Gitarre Op.19) karya Carlo Domeniconi. Ditambah dengan data-data pendukung atau eksternal berupa video pertunjukan untuk kepentingan audio visual, buku-buku, artikel dan wawancara dengan narasumber untuk kepentingan analisis dan identifikasi. Dokumen resmi eksternal adalah dokumen yang berisi bahan-bahan informasi yang dihasilkan oleh suatu lembaga sosial misalnya majalah, bulletin, pernyataan dan berita yang disiarkan kepada media masa (Moleong, 2002). Dalam penelitian kualitatif, peneliti sendiri atau bantuan orang lain adalah alat pengumpul data utama. Peneliti sebagai instrumen penelitian berfungsi dalam mengambil inisiatif yang berhubungan dengan penelitian. Inisiatif ini meliputi pencarian data, pembuatan pertanyaan untuk wawancara dan sebagai pengolah data. Dari pengertian tersebut, maka instrumen penelitian dalam penelitian ini adalah peneliti sendiri (Moleong, 2002)

\section{Hasil}

\section{Analisis Tekstual Koyunbaba karya Carlo Domeniconi bagian I Moderato}

Enharmonik Hasil analisis struktur musik pada karya berjudul Koyunbaba bagian I Moderato akan dibahas secara lebih rinci dengan menyajikan periode yang ada didalamnya. 


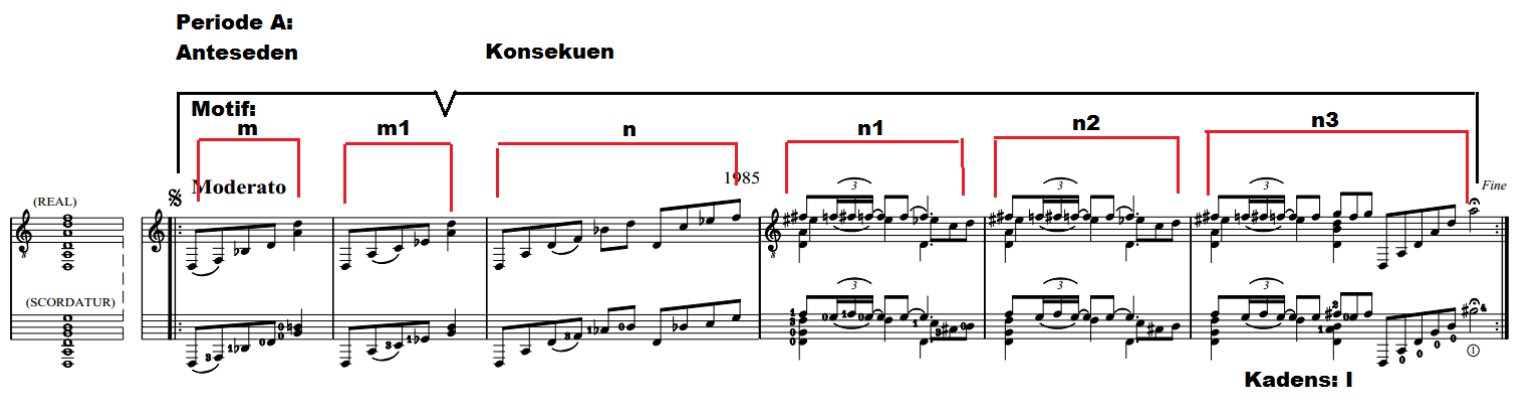

Gambar 1 Periode A

Periode A berisi enam birama yang terdapat pada birama satu sampai enam. Pada periode ini didalamnya terdapat dua anak kalimat yang merupakan anteseden pada birama satu dan dua, kemudian konsekuen pada birama tiga sampai birama enam. Kadens dalam peeriode ini dapat diidentifikasikan sebagai kadens sempurna karena berakhir dengan akor I mayor. Kemudian, untuk motif dalam periode ini ditemukan enam pola motif yaitu $m$ yang terdapat pada birama pertama, $\mathrm{m} 1$ terdapat pada birama dua dimana motif $\mathrm{m} 2$ ini adalah pengulangan motif $\mathrm{m}$ dengan penambahan teknik sekuens naik, motif $\mathrm{m} 2$ terdapat pada birama ketiga yang merupakan pengulangan motif $m$ dengan pengolahan sekuens naik dan augmentasi pada nilai nada, $\mathrm{n}$ pada birama keempat dan diulang sama persis pada birama kelima. Motif yang terakhir yaitu $n 1$ yang ada pada birama keenam dimana motif ini merupakan pengulangan dari m4 dengan pennambahan akor I untuk mengakhiri kunsekuen.

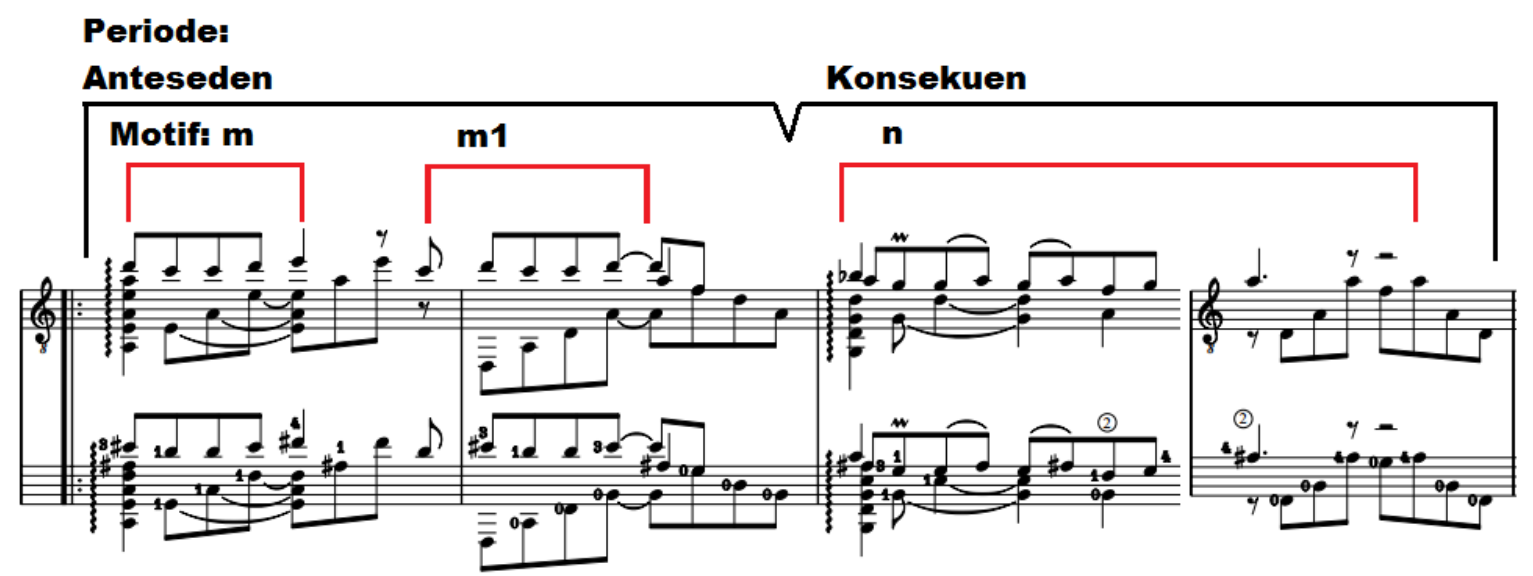

Gambar 2 Periode B

Periode B terdapat pada birama tujuh sampai birama sepuluh. Dalam periode ini anteseden terletak pada birama tujuh dan delapan dan konsekuen terletak pada birama sembilan dan sepuluh. Kemudian, motif pada kalimat ini ada tiga yaitu $\mathrm{m}$ yang terletak pada birama tujuh selanjutnya $\mathrm{m} 1$ pada birama delapan, kemudian $\mathrm{n}$ yang terdapat pada birama sembilan dan sepuluh. 


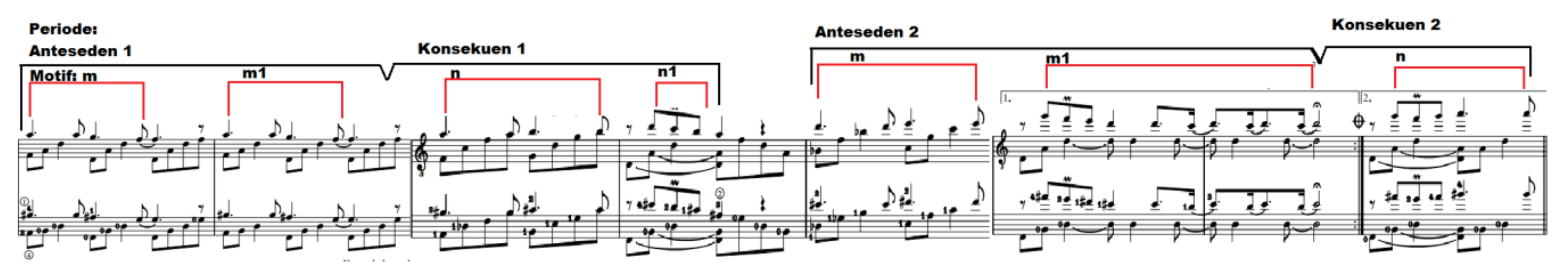

Gambar 3 Periode C

Periode $\mathrm{C}$ ada pada birama sebelas sampai delapan belas. Periode ini terdiri dari dua anteseden dan dua konsekuen. Anteseden satu berada pada birama sebelas dan dua belas kemudian konsekuen satu pada birama tiga belas dan empat belas. Selanjutnya, anteseden dua pada birama lima belas dan tujuh belas dan diakhiri dengan konsekuen dua pada birama delapan belas. Selanjutnya motif pada periode ini berjumlah tujuh motif diantaranya $m$ pada birama sebelas, $\mathrm{m} 1$ pada birama dua belas, $\mathrm{n}$ pada birama tiga belas dan $\mathrm{n} 2$ pada birama empat belas. Selanjutnya pada anteseden dua dan konsekuen dua terdapat tiga motif yaitu $\mathrm{m}$ pada birama lima belas, $\mathrm{n} 1$ pada birama enam belas dan tujuh belas dan diakhiri dengan motif $\mathrm{n} 2$ pada birama delapan belas.

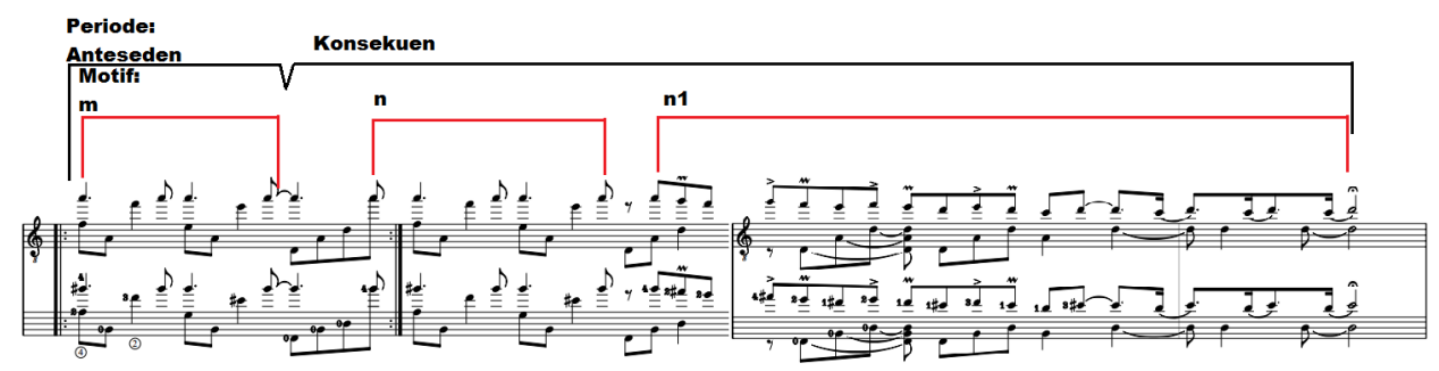

Gambar 4 Periode D

Dalam periode $\mathrm{D}$ terdapat anteseden pada birama sembilan belas dan konsekuen pada birama dalam birama sembilan belas dan hanya mempunyai satu motif pada birama yang sama. Selanjutnya pada birama dua puluh, dua puluh satu dan dua puluh dua terdapat konsekuen yang didalamnya terdapat dua motif yaitu $\mathrm{n}$ pada birama dua puluh dan $\mathrm{n} 1$ pada birama dua puluh satu dan dua puluh dua.

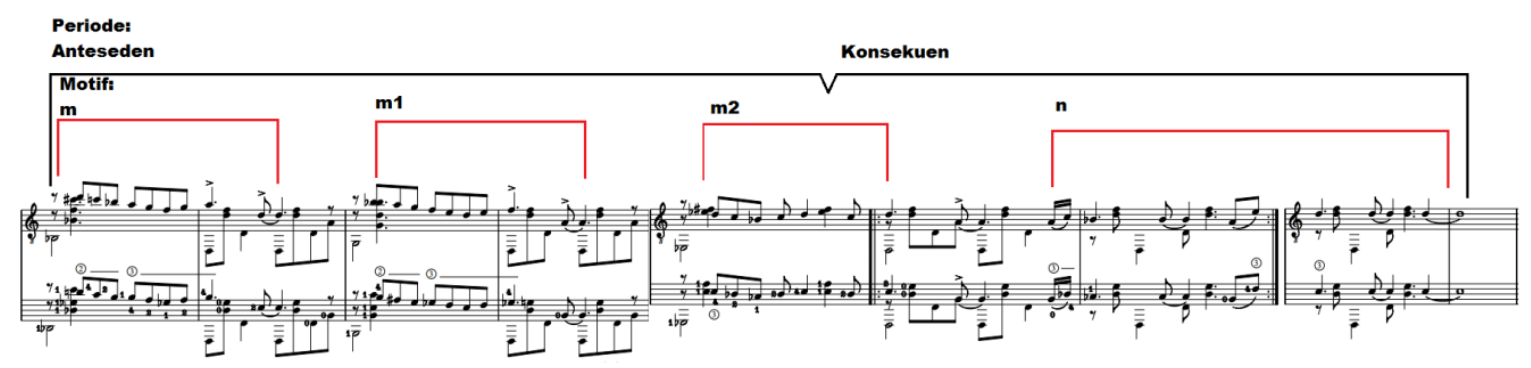

Gambar 5 Periode E 
Pada periode $E$ anteseden terletak pada birama dua puluh tiga sampai dua puluh tujuh dan dilanjutkan dengan konsekuen pada birama dua puluh delapan sampai birama tiga puluh satu. Dalam anteseden terdapat tiga motif yaitu m pada birama dua puluh tiga dan dua puluh empat, $\mathrm{m} 1$ pada birama dua puluh lima lima dan dua puluh enam, kemudian $\mathrm{m} 2$ pada birama dua puluh tujuh. Selanjutnya, pada bagian konsekuen terdapat satu motif yanitu $\mathrm{n}$ yang terdapat pada birama dua puluh delapan sampai birama tiga puluh satu.

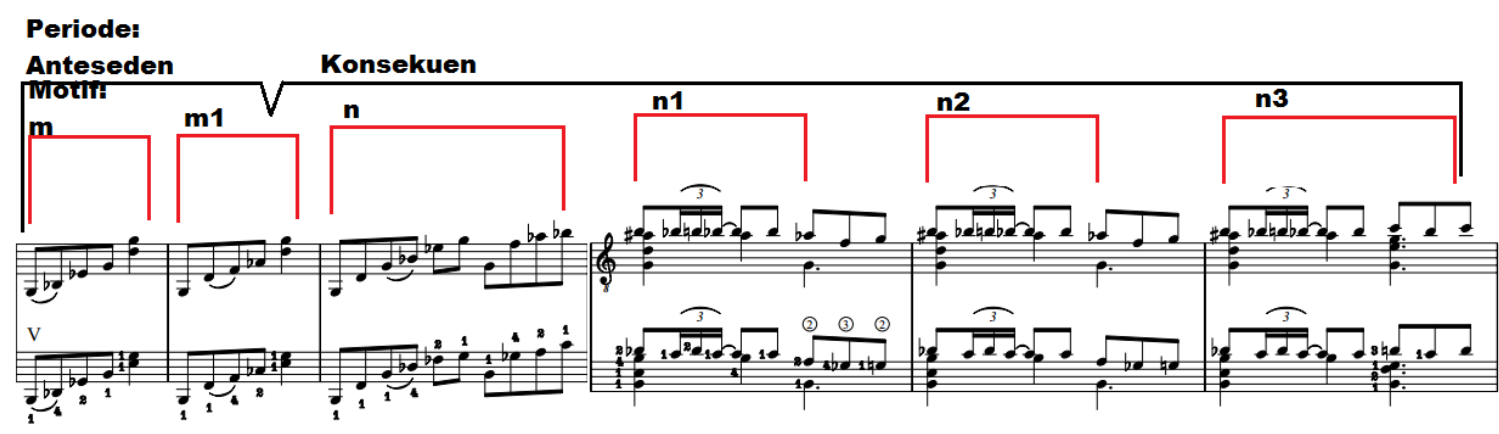

Gambar 6 Periode $A^{\prime}$

Periode $A^{\prime}$ terletak dalam birama tiga puluh dua sampai birama tiga puluh tujuh. Anteseden terletak pada birama tiga puluh dua dan tiga puluh tiga dan dilanjutkan konsekuan pada birama tiga puluh tiga sampai tiga puluh enam. Periode ini mirip dengan periode pertama namun mempunyai perbedaan pada motif terakhir yang terdapat pada birama tiga puluh tujuh.

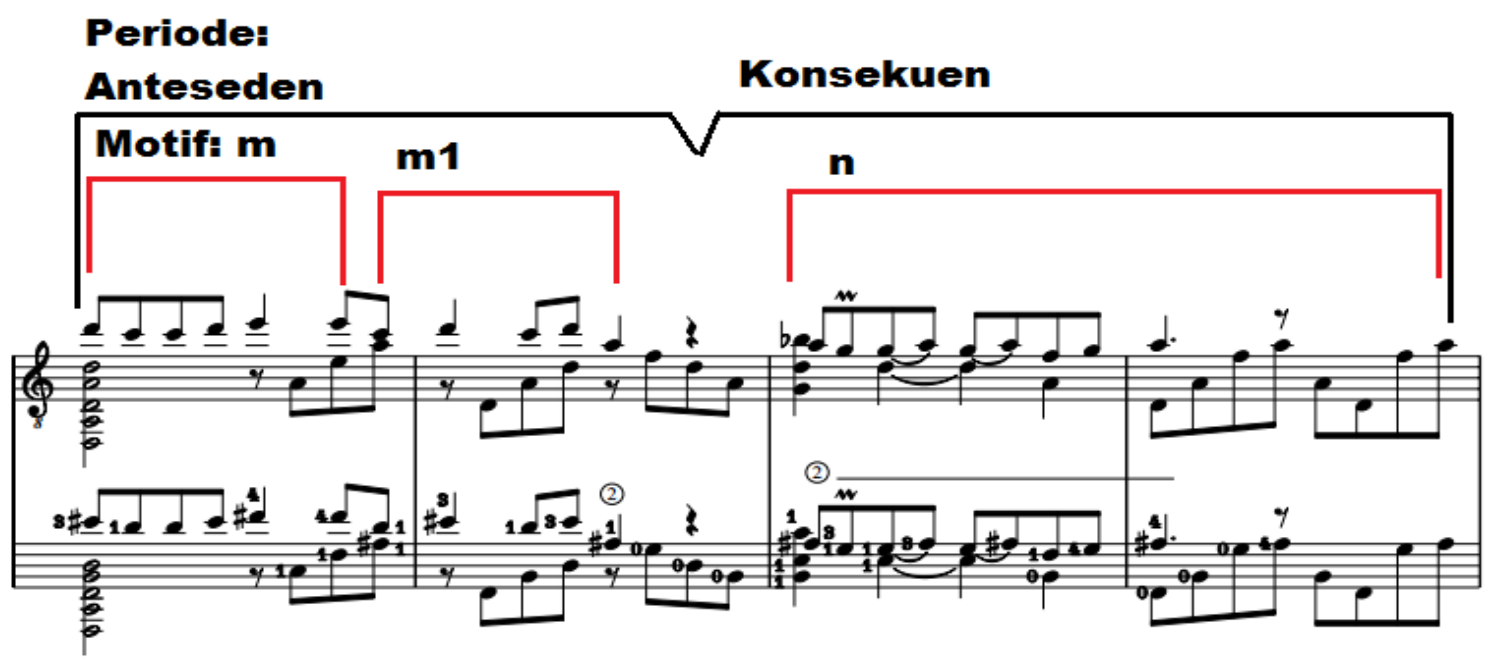

Gambar 7 Periode B'

Periode B' terdapat pada birama tiga puluh delapan sampai birama empat puluh satu. Periode ini mirip dengan periode kedua atau periode $B$. namun periode ini mempunyai perbedaan dengan penambahan pola iringan yang sedikit berbeda dengan periode $B$. 


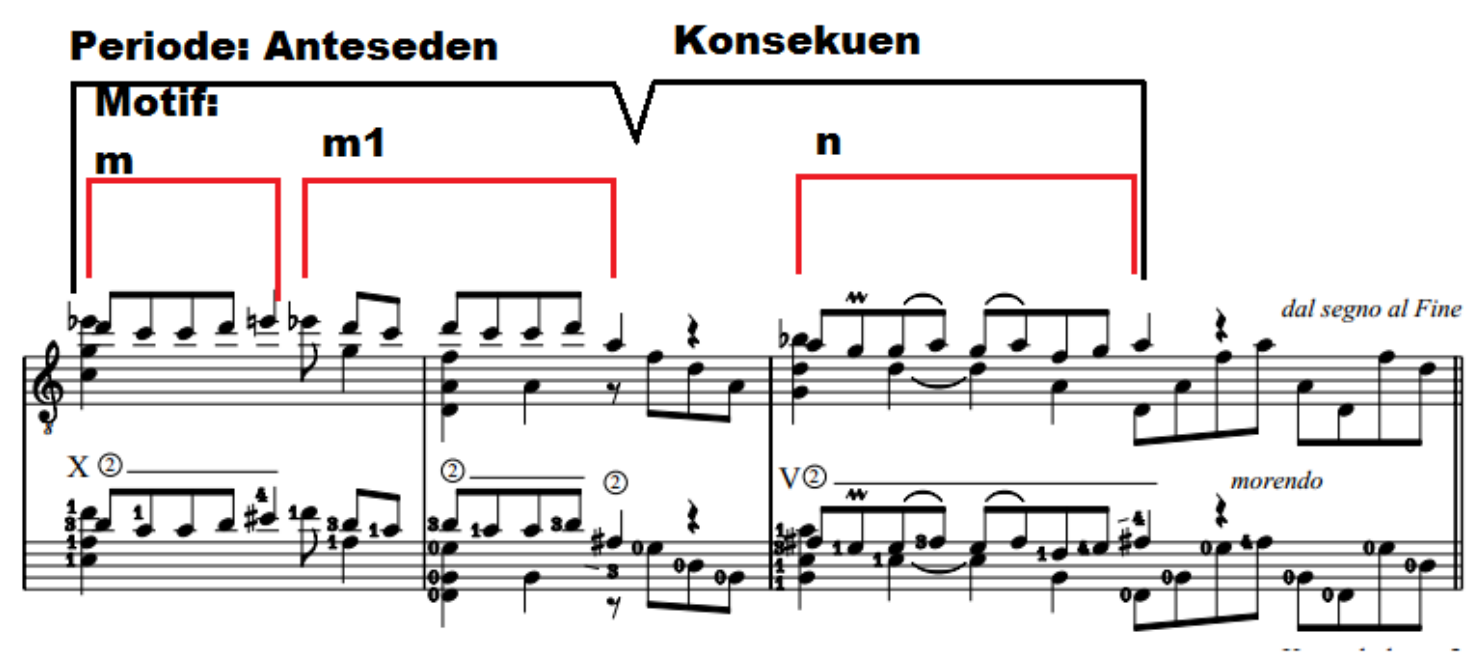

Gambar 8 Periode B"

Periode $\mathrm{B}$ " terdapat pada birama tiga puluh sembilan sampai birama empat puluh dua. Periode ini mirip dengan periode B. Namun dalam periode ini pengulangan yang dilakukan tidak seluruhnya sama yaitu dengan memberikan perubahan pada pola iringan dan sedikit perubahan pada melodi, yaitu dengan penambahan antisipasi pada motif kedua. Motif kedua dalam periode ini tidak terdapat pada kalimat B. pada akhir periode ini terdapat tanda yang bertuliskan dal segno al Fine, dimana dal segno al Fine memberikan petunjuk bahwa permainan setelah kalimat $B^{\prime \prime}$ diharuskan untukkembali kepada tempat yang ditandai segno dan berakhir pada tanda Fine. Ini juga merupakan akhir dari movement I (Moderato).

\section{Pembahasan}

\section{Teknik Scordatura dalam Bagian I Moderato}

Secara umum Koyunbaba merupakan karya untuk solo gitar yang ditulis oleh komposer asal Italia yaitu Carlo Domeniconi. Karya ini mulai dibuat di kota Istanbul, Turki dan selesai pada tahun 1985 di kota Berlin, Jerman. Karya Turki yang paling populer adalah Koyunbaba yang diselesaikan pada tahun 1985 dimana karya ini merupakan karya solo empat gerakan yang telah direkam dan dibawakan secara teratur oleh banyak gitaris klasik terbaik dunia termasuk John Williams, David Russel dan Xuefei Yang, Harries (2014). Karya ini pada awalnya merupakan sebuah improvisasi yang kemudian dituliskan ke dalam teks musik atau partitur. Komposisi ini terdiri dari empat bagian atau gerakan yang terdiri dari I Moderato, II Mosso, III Cantabile, dan IV Presto

Analisis bentuk dan struktur yang terdapat pada bagian pertama dalam karya koyunbaba, yaitu I Moderato menjadi penting dan menarik untuk dibahas karena bagian ini merupakan pembuka dari satu karya Koyunbaba yang dapat dikatakan sebagai karya yang cukup panjang. Melalui pemahaman pada bagian pertama ini, diharapkan pemain gitar dapat memahami pintu gerbang dari sebuah karya Koyunbaba ini melalui bagian pertama I Moderato. Selain itu, dengan disajikannya analisis tekstual ini diharapkan dapat membantu pemain gitar maupun semua pihak yang membutuhkan untuk dapat memahami teks I Moderato ini secara terperinci dengan mengamati setiap bagian yang telah diklasifikasikan dari periode hingga bagian terkecil yaitu motif. 
Pada bagian pertama I Moderato terdapat empat puluh dua birama dan delapan periode. Periode disini digunakan sebagai pengelompokan motif yang telah tersusun menjadi sebuah kalimat utuh. Di dalam setiap periode terdapat anteseden dan konsekuen. Menariknya, dalam I Moderato ini banyak dijumpai periode yang tidak simetris, artinya dalam satu periode dapat berisi dua anteseden dan ditutup hanya dengan satukonsekuen, hal ini bisa dikaitkan dengan latar belakang ditulisnya karya ini yang pada awalnya adalah sebuah permainan improvisasi gitar. Karya ini juga menggunakan penulisan yang berbeda dengan penulisan pada umumnya yaitu dengan menggunakan scordatura.

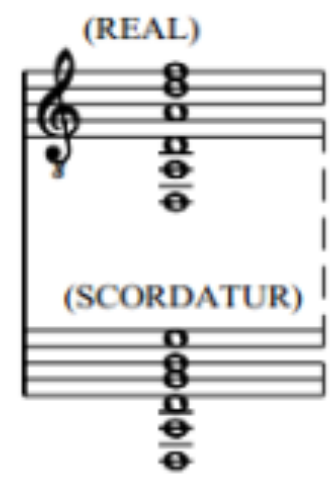

Gambar 9 Scordatura

Pengertian scordatura dapat dilihat dalam (Sadie, 2001) yang menyatakan bahwa scordatura adalah kondisi yang diterapkan sebagian besar pada kecapi, gitar, biola, dan keluarga biola untuk menunjuk penyeteman selain penyeteman normal, atau yang sudah lazim (Sadie, 2001). Dalam karya yang sedang dibahas ini. Komposer memberikan scordatura untuk mempermudah proses pembacaan notasi dan untuk mempermudah memainkannya. Scordatura hanya digunakan pada komposisi atau transkrip karya tertentu yang mempunyai tujuan untuk memberikan kesan tertentu.

Hasil dan pembahasan dalam tulisan ini adalah upaya untuk memberikan sumbangan pemikiran dalam wilayah interpretasi musik yang bersumber dari teks atau partitur sebuah karya musik, dalam hal ini teks yang di maksud adalah teks dari I Moderato yang merupakan bagian pertama dari Koyunbaba karya Carlo Domeniconi, dimana Domeniconi merupakan komponis gitar klasik yang banyak diminati karya- karyanya baik untuk kepentingan pertunjukan maupun penelitian. Seperti diungkapkan Collin Harries bahwa ketersediaan komposisi Domeniconi dan penghargaan yang tinggi di mana ia dipegang oleh sejumlah gitaris paling terkemuka saat ini, merupakan indikasi akan pentingnya musiknya dalam repertoar gitar klasik (Harries, 2014).

\section{Kesimpulan}

Berdasarkan hasil dan pembahasan di atas, karya Koyunbaba merupakan sebuah karya yang di dalamnya terdapat empat bagian, dimana bagian- bagian tersebut mempunyai bentuk dan struktur masing- masing. Pada bagian pertama bentuk dan struktur terdiri atas delapan periode dimana motif-motif yang dituliskan merupakan motif yang berpotensi diulang pada bagian-bagian selanjutnya. Bagian pertama ini juga berfungsi sebagai introduction atau pengenalan terhadap karya koyunbaba ini. Dalam bagian pertama ini ditemukan motif-motif yang cukup beragam karena dalam sejarahnya karya ini merupakan hasil improvisasi yang dituliskan ke dalam partitur. Hal ini menyebabkan bagian pertama I Moderato ini memberikan 
kesan seperti memainkan gitar tanpa partitur. Dalam partitur atau teks Koyunbaba ini ditemukan representasi bentuk musik suita dimana bagian pertama berfungsi sebagai pembuka suita.

Pada karya ini juga ditemukan penggunaan tanda-tanda yang unik yang jarang digunakan pada karya musik yang lain. Diantaranya adalah penggunaan scordatura. Scordatura menjadi bagian penting dalam karya ini karena berfungsi sebagai petunjuk arah dalam pembacaan partitur. Scordatura digunakan karena dalam karya ini sistem penalaan atau tunning yang dipakai tidak menggunakan system tunning pada umumnya. Jika pada umumnya tunning gitar adalah E-B-G-D-A-E maka dalam karya ini tunning yang digunakan adalah F-D-A-D-A-D. Poin terakhir yang dapat disampaikan adalah Carlo Domeniconi telah tampil sebagai koponis dengan gaya yang berbeda dengan pengaruh musik-musik diluar musik klasik yang dikembangkan dengan gaya yang didapat dari pengalaman hidupnya. Seperti karya koyunbaba ini, yang terinspirasi dari warna-warna musik tradisional Turki yang didapat ketia ia datang dan menetap di Turki.

\section{Referensi}

Andaryani, E. T. (2019). Pengaruh Musik Sebagai Moodboster Mahasiswa. Musikolastika: Jurnal Pertunjukan Dan Pendidikan Musik, 1(2), 109-115.

Firmansyah, F. (2015). Bentuk Dan Struktur Musik Batanghari Sembilan. Ekspresi Seni: Jurnal Ilmu Pengetahuan Dan Karya Seni, 17(1), 83-102.

Harries, C. (2014). The Solo Guitar Music Of Carlo Domeniconi: An Exploration Of The Diverse Influences. Waterford Institute Of Technology.

Hidayatullah, R. (2020). Kreativitas Dalam Pendidikan Musik: Berpikir Divergen Dan Konvergen. Musikolastika, 2(1), 1-7.

Moleong, L. J. (2002). Metode Penelitian Kualitatif. In Bandung: Rosda Karya.

Muhammad, S. (2003). Ensiklopedia Musik Klasik. Yogyakarta: Adicita Karya Nusa, Cisya Kencana Orchestra.

Niswati Khoiriyah, S. S. Si. (2017). Pemanfaatan Pemutaran Musik Trhadap Psikologis Pasien Pada Klinik Ellena Skin Care Di Kota Surakarta. Jurnal Seni Musik Unnes.

Parmadie, B. (2016). Cultural Studies: Sudut Pandang Ruang Budaya Pop. An1mage Jurnal Studi Kultural, 1(1), 50-57.

Paulus, J., Müller, M., \& Klapuri, A. (2010). State Of The Art Report: Audio-Based Music Structure Analysis. Ismir, 625-636.

Prier, K.-E., \& Widyawan, P. (2011). Roda Musik Liturgi. Yogyakarta: Pusat Musik Liturgi.

Putra, I. P. A. S. S. (2019). Analisis Komposisi Musik "Kuasa Tanah." Journal Of Music Science, Technology, And Industry, 2(1), 49-84.

Sadie, S. (2001). A Cappella. The New Grove Dictionary Of Music And Musicians. 2nd Ed. New York: Macmillan Publishers Limited. 
Sinaga, F. S. S., Maestro, E., Marzam, M., \& Yensharti, Y. (2019). Software Sibelius Sebagai Alternatif Penulisan Notasi Musik Di Era Millenial. Musikolastika: Jurnal Pertunjukan Dan Pendidikan Musik, 1(1), 1-6. Http://Musikolastika.Ppj.Unp.Ac.Id/Index.Php/Musikolastika/Article/View/11

Stein, L. (1962). Structure And Style: The Study And Analysis Of Musical Forms. SummyBirchard Company.

Sugiyono, P. (2011). Metodologi Penelitian Kuantitatif Kualitatif Dan R\&D. Alpabeta, Bandung.

Wardani, A. W. (2020). Analisis Struktur Lagu" Bohemian Rhapsody" Karya Freddie Mercury (Aransemen Oni Krisnerwinto).

Widyanta, N. C. (2019). Makna Metaforis Yang Terkandung Dalam Lagu "Tikus-Tikus Kantor" Karya Iwan Fals. Musikolastika: Jurnal Pertunjukan Dan Pendidikan Musik, 1(2), 52-64.

Winangsit, E., \& Sinaga, F. S. S. (2020). Writing Music Through Parnumation 3.0 In The Musical Activities Learning Process. 1st International Conference On Lifelong Learning And Education For Sustainability (Iclles 2019), 31-34.

Yensharti, Y. (2019). Pengaruh Bias Pemahaman Substansi Dasar Teori Musik Terhadap Kemampuan Praktek Instrumen Gesek Di Sendratasik Unp. Musikolastika: Jurnal Pertunjukan Dan Pendidikan Musik, 1(1), 22-29.

Yuniarko, A. B. (2020). Analisis Teknik Permainan Gitar Klasik Pada Lagu Maxixe Karya Agustin Barrios Mangore. 